\title{
NOTAS MARGINALES A LOS POETAS DOMINICANOS DE LA GENERACION DE 1965, AMPLIADAS
}

\author{
POR \\ ALBERTO BAEZA FLORES
}

UN PUNTO DE PARTIDA PERSONAL EN LA INVESTIGACIÓN LITERARIA

En el tomo IV de mi obra La poesía dominicana en el siglo XX, Historia, crítica, estudio comparativo y estilístico ${ }^{1}$, dediqué los capítulos sexto y séptimo al análisis de los poetas dominicanos de la generación que he propuesto como de 1965. En los capítulos décimo - donde estudio el pluralismo y las vanguardias - y undécimo, que se refiere a los poetas en provincias, hay numerosas páginas sobre los poetas de esta generación ampliada. En el tomo II de la obra, cuando en los capítulos iniciales me refiero a las generaciones, también estudio la ubicación y la denominación de estos poetas de 1965.

En la Colección Orfeo, editada por la Biblioteca Nacional de Santo Domingo y dirigida por el entonces director de la Biblioteca, el poeta, ensayista y crítico Cándido Gerón, publiqué un grueso volumen sobre estos poetas: Los poetas dominicanos del 1965. Una generación importante y distinta ${ }^{2}$, y he hablado de una «generación ampliada» para incluir

${ }^{1}$ Alberto Baeza Flores, La poesía dominicana en el siglo XX. Historia, crítica, estudio comparativo y estilístico. Brigadas Dominicanas. Baluarte. Testimonio. Poesía Patriótica, Social y Revolucionaria. Los Poetas de 1965. El Pluralismo y las Nuevas Vanguardias. Los Poetas en Provincias. Consideraciones Finales. Apéndices y Bibliografía (1961-1980) (Santo Domingo, República Dominicana: Colección Orfeo, 1986).

${ }^{2}$ Alberto Baeza Flores, Los poetas dominicanos del 1965. Una generación importante y distinta (Santo Domingo, República Dominicana: Colección Orfeo. Biblioteca Nacional, 1965). Con «A manera de introducción», de Cándido Gerón, director de la Biblioteca Nacional, contiene además: Bibliografía activa y pasiva de los poetas dominicanos de la generación de 1965, ampliada desde la página 469 hasta la página 484. 
a 1o que pudiéramos llamar «las últimas consecuencias» de esta generación lírica y sus postreras resonancias.

En la medida en que adquirimos un poco de mayor perspectiva temporal -aunque los acontecimientos histórico-políticos, socioculturales, éticos, nacionales, sociopsicológicos, están aún demasiado próximos a nosotros- comprendemos que 1965 es un año de una polarización, de una cristalización del sentimiento nacional dominicano, a raíz de la intervención extranjera de abril de ese año.

No es mi intención internarme en el análisis de los enfrentamientos de factores, circunstancias nacionales y extranacionales histórico-políticas, tanto de la intervención de 1916 - ocurrida durante la Primera Guerra Mundial y siendo la República Dominicana y Haití una de las llaves del Caribe, junto a Cuba y Puerto Rico- como de la intervención de 1965, en medio de la tensión Este-Oeste, después de la proclamación del régimen del comandante Fidel Castro, en mayo de 1961, como marxistaleninista y después de la crisis mundial de los cohetes con cabeza atómica, instalados en octubre de 1962, en territorio cubano, por la Unión Soviética. He historiado la primera en mi ensayo «Don Federico Henríquez y Carvajal: un siglo de conducta y de valor», en el Lyceum de La Habana, el 16 de septiembre de 1948, y en Revista de La Habana, número 50, octubre de 1946. Y he analizado los acontecimientos de abril/mayo de 1965 en las revistas Política, de Caracas, Venezuela, y Mañana, de París, con los ecos aún frescos de los acontecimientos.

Ya se ve, por la sola referencia, que el ajedrez de la política mundial no es ajeno a que una generación lírica sea identificada por la resonancia que las circunstancias nacionales e internacioales proyectan sobre unos jóvenes creadores literarios.

La década de los años sesenta es, para la vida sociopolítica y sociocultural dominicana, la que marca, históricamente, el final de la era del generalísimo Trujillo, al menos simbólicamente, por el asesinato del llamado benefactor. Continuada con la elección democrática y mayoritaria, en 1963, del profesor Juan Bosch; seguida por el golpe de Estado y por la Junta de Gobierno (1963-1965), por la Revolución de Abril de 1965, el gobierno de Héctor García Godoy (1965-1966) y por los doce años de la nueva presidencia de Joaquín Balaguer, que empiezan en 1966, pues Balaguer había encabezado el poder ejecutivo desde 1960 a 1962.

Los acontecimientos histórico-políticos e histórico-sociales dominicanos, en la década de los años sesenta, tendrán no poca influencia en los tonos, los temas, el lenguaje, los factores psicológicos y las ambientaciones culturales del núcleo de los poetas de la generación de 1965. Son las circunstancias, en el concepto orteguiano, y es el espacio-tiempo histórico, 
de movimiento einsteiniano, que analizó en uno de sus libros Víctor Raú1 Haya de la Torre hace años.

Naturalmente que en un momento de la historia de un país las generaciones coexisten - aunque desde sus diversos niveles de tiempo- y los acontecimientos nacionales dominicanos promueven también huellas, ecos, reacciones, en los poetas independientes de 1940 , en los poetas de «La Poesía Sorprendida», en los de la generación de 1948 y en los que pudiéramos llamar los «independientes de la generación de 1950», que, desde un punto de observación, vienen a estar un tanto inmersos en los poetas de 1948, aunque son diversos, diferentes en el mensaje y proyección, y que resultan, cronológicamente, demasiado anticipados para ser incorporados a los poetas de 1965. Las líneas de diferenciación son, a veces, sutiles, ligeras, pero estos poetas, a los que cabe llamar «los independientes de 1950» —entre los que cuento a Manuel Mora Serrano, a Ramón Francisco y a otros-, cristalizan antes que aparezca la vanguardia de los poetas de 1965, con René del Risco (San Pedro de Macoris, 1936-1972), Juan José Ayuso (La Vega, 1940), Miguel Alfonseca (1942) y otros que publicarán más adelante.

\section{UNAS CARACTERÍSTICAS, UNAS PROYECCIONES}

Si nos alejamos un poco en busca de perspectiva, observaremos que en la primera etapa de esta generación de poetas dominicanos de 1965 hay dos oleajes, que se encuentran en el centro de la primera presencia generacional: un neorrealismo, con raíces en el cine neorrealista y en poetas dominicanos independientes de los años cuarenta, los ecos de una poseía social a flor de piel, y, por otra parte, las circunstancias de un mundo con los medios de comunicación colectivos cada vez más acelerados. No en vano Marshall McLuhan ha titulado a uno de sus libros claves El medio es el mensaje, que parece una consigna epocal. $Y$ no en vano, más adelante, hablará de «la aldea global». Todo esto, de manera consciente o en el inconsciente, está en los poetas de esta generación dominicana, que recibe la resonancia de la guerra de abril, pero, al mismo tiempo, la explosión cultural que significa, para la cultura occidental, la década de los años sesenta.

Si olvidamos la influencia de las circunstancias nacionales, del área caribeña, continentales y mundiales, se nos escapará la temática y el mensaje que nos dan estos poetas. También se nos alejarán, de nuestro contacto y goce estético, los caminos de la proyección y de la maduración de esta generación que responde a su hora nacional, a su momento 
continental y a la resonancia planetaria. Los tonos y los temas de los poetas de 1965 corresponden a las características de sus escenarios.

Asimismo, puede tenerse en consideración que la poesía iberoamericana, española, francesa, alemana, norteamericana, paralela a la de los poetas dominicanos de 1965, se enfrenta y asimila experiencias derivadas del Mayo francés y otros movimientos coetáneos: la aparición del «hippismo», la renovación de las artes plásticas y de la música. Las bienales de arte de París son un termómetro estético. El cine vérité ofrece un nuevo tratamiento de la imagen fílmica. En otros aspectos, hemos llegado a una «liberación», que se expresa también a través de una nueva falta de inhibición sexual en la vanguardia de la nueva generación; en el ensayo de drogas alucinógenas; en los grandes festivales internacionales de la música «pop» como «explosiones colectivas» y fiestas multitudinarias de todos los sentidos «en libertad» y en otras formas de alcanzar un «más allá». Algunas vanguardias se hacen peregrinas y las culturas del Oriente - milenarias - y de Occidente, se aproximan. La India ejerce una influencia imantadora, desde los instrumentos de los Beatles hasta las experiencias de poetas «que se liberan».

Esto llega, como por rebotes, a los poetas dominicanos - y a otros de nuestra América y de España--, porque el planeta se ha ido intercomunicando a través de los medios de comunicación colectiva. Estamos en una civilización de pantallas, de imágenes en movimiento. En la era posatómica hemos entrado en la edad cibernética, electrónica, donde no han sido superados grandes conflictos planetarios: el hambre, la subalimentación en zonas en vías de desarrollo, los ataques contra la ecología, las crisis nacionales y continentales, las diferencias Este-Oeste y Norte-Sur, el terrorismo en sus variadas formas y la guerra psicológica o guerra ideológica en sus diversos matices; pero con todos estos conflictos, encrucijadas y confrontaciones continuamos en «la aeronave tierra», mientras las superpotencias envían naves al espacio sideral y se van multiplicando los satélites artificiales.

En medio del choque de tantas corrientes distintas y, a veces, contrarias, se agudizan las expresiones del humor como salida. En estos poetas dominicanos de 1965, estas notas de humor sentimental son bastante visibles. Un humor que es, a veces, un tanto desesperado desde su testimonio, y otras veces es una mera fe de vida o testificación social, existencial. 


\section{EL CALEIDOSCOPIO DE LOS CAMBIOS}

Las universidades jugarán un papel fundamental en la formación cultural de una parte importante de los poetas de 1965. La República Dominicana establecerá, primero en Santiago de los Caballeros, un segundo polo cultural en torno a la Universidad Católica Madre y Maestra y contará con la visión editorial de Héctor Incháustegui Cabral. Más tarde surgirán la Universidad Nacional Pedro Henríquez Ureña en Santo Domingo y la Universidad Central del Este (UCE) en San Pedro de Macorís. La tarea editorial de estas universidades está, mientras escribo, a cargo de dos poetas importantes del grupo de «La Poesía Sorprendida»: Mariano Lebrón Saviñón en la UNPHU y Freddy Gatón Arce en la UCE. Hay que agregar que el poeta y ensayista Cándido Gerón, como director de la Biblioteca Nacional, creó un sólido y activo centro editorial y un escenario de diálogo e intercambio vivo de actividades poéticas. La función de la Colección Orfeo es de una importancia que crecerá con la perspectiva de los años.

Desde la Universidad Nacional Autónoma de Santo Domingo han surgido talleres literarios que dan también un tono de apoyo a la tarea de los poetas de 1965. El antecedente es el taller literario que funcionó desde 1943 en adelante, cuando el movimiento de «La Poesía Sorprendida» sesionó en la casa del poeta Franklin Mieses Burgos («La Casa de la Poesía»).

Es importante la relación de las universidades con los poetas de 1965 , y es significativo que algunos de ellos se relacionen con los medios de información y publicidad, como es el caso de Alfonseca y Ayuso, y otros, como es el caso de Tony Raful (1951), Andrés L. Mateo y Pedro Peix (Santo Domingo, 1952), mantienen programas radiales, como «Peña de Tres», para la proyección poética hacia las mayorías.

Manuel Mora Serrano, por su parte, asume un papel misionero para dar a conocer a los poetas que trabajan en las provincias.

Los poetas de 1965 promueven encuentros, coloquios y mesas redondas aprovechando los buenos escenarios de la Universidad Nacional Autónoma de Santo Domingo y de la UCMM de Santiago de los Caballeros. Estos son modos nuevos que no podían ser ejercitados por los poetas de «La Poesía Sorprendida», "Independientes de 1940» y "Generación de 1948» durante los tres decenios del reinado de Trujillo.

Son factores, circunstancias, que interesan a la sociología de la literatura, pero el quehacer poético, y en especial el de los poetas de 1965, no está separado, aislado, de las comunidades humanas, del latido na- 
cional, continental y planetario, y es necesario atender a los factores que contribuyen a explicar la actividad de una generación, como, en este caso, la de los poetas dominicanos de 1965.

\section{OBSERVACIONES Y ESTIMACIONES DEL CONJUNTO GENERACIONAL}

De «anti-antología» calificó Pedro Conde a su Antología informal: la joven poesía dominicana ${ }^{3}$. Pese a los reparos diversos sobre los poetas. antologados y al calificativo irónico de "anti-antología», hay en ella, a modo de conclusión, unas líneas de fe abiertas hacia el futuro: "Lo que se ha hecho no carece de valor. Pero lo importante es lo que resta como potencialidad a desarrollar. La época ofrece oportunidades que no cono-. cieron otras generaciones. Lo que tenemos entre manos puede llegar a ser grande. En este sentido somos optimistas» (p. 11).

Hay que señalar que la antología de Pedro Conde destaca, acertadamente, como pioneros, a Miguel Alfonseca, Juan José Ayuso, Jacques Viau Renard, René del Risco Bermúdez, y señala la presencia, en la generación, de poetas como Norberto James Rawling, Andrés L. Mateo, Antonio Lockward Artiles, Wilfredo Lozano, Mateo Morrison, cuyas obras contribuirán a la identificación del conjunto generacional.

La generación de 1965 produce una primera visión desde adentro con motivo de la tesis de grado académico de Enriquillo Sánchez: $L a$ poesía bisoña (Poesía dominicana 1960-1975). Reseña y antología ${ }^{4}$. Bisoño es el inexperto en cualquier arte y oficio, y dejé constancia, reiterada* mente, en La poesía dominicana del siglo $X X$, que estaba en desacuerdo con calificar de bisoña a una poesía joven, de calidad, como la dominicana.

Los estudiosos de la poesía dominicana podrán advertir, ante la reseña o estudio inicial de la obra de Enriquillo Sánchez, que se trata de una verdadera ruptura al enfocar y analizar la aportación generacional, empezando por el título festivo y juguetón. Y no es que exista relación entre esta generación y el movimiento Dadá u otro de las vanguardias, después.

${ }^{3}$ Pedro Conde, Antología informal: la joven poesía dominicana (Santo Domingo: Editora Nacional, s. f.). El libro aparece sin fecha de impresión. La Biblioteca de la Universidad Católica Madre y Maestra, que según se me ha informado recibió la antología a poco de aparecer, señala como fecha de entrada el 7 de diciembre de 1971.

${ }^{4}$ Enriquillo Sánchez, La poesía bisoña (Poesia dominicana 1960-1975), Facultad de Humanidades (Departamento de Letras), tesis para optar al título de licenciado en letras. Profesor consejero: Juan Bosch, $280 \mathrm{pp}$. mimeografiadas, policopiadas, $27,5 \mathrm{~cm}$. La única fecha posible - sobre su publicación- es la del prólogo: octubre de 1974 (p. 135). El estudio o introducción llega hasta la página 135. 
de la Primera Guerra Mundial, ni de los movimientos producidos en el Cono Sur relacionados con el creacionismo y el ultraísmo, y ni aun con el tardío grupo de los runrunistas chilenos (Morgado y sus compañeros), que irrumpirán en los finales de los años veinte y en los comienzos de los treinta, y hago la cita valiéndome de mi memoria y sin tener delante los libros «del runrunismo chileno».

Más bien hay que pensar en otra «onda», para decirlo en el lenguaje de los sesenta/setenta. Hay que pensar en las «explosiones» de los sesenta: en el Mayo francés, la liberación sexual, en los ecos de City Lights Books (1953) de Lawrence Ferlinghetti y Howl de Allen Ginsberg, que no llegarán de inmediato, sino a modo del reflujo de una ola lenta que tocará también a los inquietos y alertas en el Caribe, en España y en Asia. Jack Kerouac y el intenso Bob Kaufman, de la beat generation, llegarán también, directa o indirectamente. Está «el fenómeno» de la canción protesta en ambas Áméricas y en España. Y está también el free jazz, como explosión y liberación musical (Charlie Mingus, Eric Dolphy, Ornette Coleman, Don Cherry, Albert Ayler). Hago estas referencias de manera muy simbólica y a modo de lenta extensión de la renovación musical y consecuencias en la cultura epocal, en general. Se trata de una comunicación, en «la aldea global», que alcanza a vanguardias rebeldes culturales, aun en sociedades como las de las democracias populares -especialmente en Polonia - y en un «hippismo» clandestino soviético, que vi al pasar por Moscú.

\section{Síntomas, Símbolos, ACTITUdES, EXPRESIONES}

Lo que los poetas postumistas — con Moreno Jimenes y Andrés Avelino al frente- proclamaban en El Día Estético era, en el fondo, un enfrentamiento con ciertas vanguardias europeas, una búsqueda de una salida del modernismo hacia un posmodernismo cargadamente neo-realista y nacionalista y con una brillante nota de mesianismo en Moreno Jimenes. Este gran poeta dispar, trotapueblos, mesiánico, metafísico, popular y atormentado, siempre abierto $-\mathrm{y}$ que infortunadamente para el mayor y mejor conocimiento de su obra y su acción poética nunca salió de su tierra natal-, llega en la década de los años cuarenta, con el joven poeta Mariano Lebrón Saviñón y con el que esto escribe, a una poesía colectiva, con trasfondos surrealistas o parasurrealistas, que edita cuatro folletos en 1943 y 1944: Los triálogos, poesía a tres voces. Pero tanto en los pronunciamientos postumistas como en los de Los triálogos - voz que no recogerá el diccionario-, los tonos son lo contrario del humor de Enriquillo Sánchez en su obra sobre los poetas de 1960-1975. 
«La Poesía Sorprendida» aparece y se desarrolla en medio de la Segunda Guerra Mundial, en la lucha contra el nazifascismo, y su consigna de «Poesía con el Hombre Universal» corresponde a las circunstancias históricas planetarias. También su pronunciamiento y su estupor ante Hiroshima. Son problemas que conmueven al hombre de nuestro tiempo y a la cultura universal.

Lo que de los poetas independientes de 1940 está en Cuadernos Dominicanos de Cultura, especialmente el número antológico sobre el existencialismo, y lo que los poetas de 1948 expresan en sus pronunciamientos, siempre muy serios, es una fe de vida sobre el momento nacional, continental y universal que todos vivimos.

¿Qué sucede, en cambio, con el tono de Enriquillo Sánchez, en su libro sobre los poetas de su generación, y qué surge desde esa misma generación? «La poesía bisoña —dice Enriquillo Sánchez, en la página primera - ha sido una tropa con dos o tres sargentos e innumerables rasos.»

Al final de su ensayo, declara Enriquillo Sánchez: «Ahora bien, con la joven poesía dominicana debería morir la poesía bisoña. Todo lo que se ha dicho es una contribución gentil a darle el tiro de gracia, porque de todos modos, a pesar de los esfuerzos, no vamos a cometer el homicidio. Ella nació muerta. Sólo espera el tiro de gracia. Gracias.»

No es posible, y si así lo hiciéramos, iríamos errados si tomáramos al pie de la letra esta declaración de Enriquillo Sánchez, uno de los espíritus brillantes de esta generación y un creador lírico de gran inquietud intelectual y experiencia, y sería suficiente su extenso e inquieto poema «Maguita», que requeriría un largo análisis por las virtudes y excelencias líricas que contiene.

En esta generación de 1965 advertimos plurales y paralelas realizaciones, en tonos y temas vivos y valiosos. Hay, en un grupo, una poesía de proyección de militancia social que Mateo Morrison ha llevado a los talleres y a los actos culturales en los barrios populares. Tony Raful ha conseguido una voz antigua y futura, a la vez, desde las raíces del Oriente Medio aclimatadas en el Caribe, con la herencia asimilada de una valiosísima poesía, donde ha unido lo social y lo profético, lo testimonial y la crónica nacional/epocal.

La poesía de exploración lo ha sido por dos vías: el pluralismo de Manuel Rueda (el joven ayer del movimiento de «La Poesía Sorprendida»), que me parece que ha ido más allá de las exploraciones de Octavio Paz, tan valiosas, y esto es marcar una gran importancia para la vanguardia de las vanguardias en el pluralismo de Manuel Rueda y esa máquina o computadora o «bloque» de una nueva estética. Del pluralismo 
de Rueda sale el pluralismo existencialista de Cayo Claudio Espinal. Desde la otra vía, más apegada a Paz y más separada de Rueda, está la experimentación de Enrique Eusebio.

Lo que en Vallejo era internidad - provincia adentro del alma sola y telúrica - es en José Enrique García no repetición, sino personalísimo mensaje de autenticidad de una nueva exploración hacia los materiales y galerías del alma.

Norberto James, Wilfredo Lozano, Andrés L. Mateo, Alexis Gómez, Federico Jovine Bermúdez, Miguel Aníbal Perdomo, José Molinaza, Pedro Vergés, Rafael García Bidó, Juan Carlos Mieses - y aún hay otros mundos líricos en esta generación- representan diversas vías de consolidación y de exploración, de técnicas y modos diversos para enfocar el hecho lírico.

Una característica que podemos señalar en estos poetas de 1965 es que, al leerlos, nos damos cuenta de que las imágenes — cine, televisión, fotografía fija- han ido creando un clima de penetración viva en la sensibilidad poética de estos creadores. Hay que agregar, también, la relación entre las artes plásticas dominicanas y estos poetas, que, cuando los movimientos de la Revolución de abril de 1965, crearon una coincidencia de expresiones complementarias.

En lo que es expresión lírica del mundo de la mujer y actitud testimoniadora y liberadora, la poesía dominicana encuentra en la generación de 1965 una constelación valiosa y decisiva, que se explica por factores sociopolíticos, socioeconómicos, sociopsicológicos y socioculturales. Jeannette Miller, Soledad Alvarez, Sally Rodríguez, Josefina de la Cruz, Sabrina Román, Taiana Mora Ramis, que es la voz más joven de esta generación ampliada, la voz casi niña, y el grupo de mujeres poetas, que puede funcionar como un taller de poesía, representan una aportación de la poesía dominicana, femenina, en la extensa área caribeña, donde se asoma el mundo centroamericano ${ }^{5}$.

Al leer a Alan Watts - un pensador que es puente entre las culturas occidentales y orientales- advierto lo que de las viejas culturas orientales pasa a nuestras culturas, especialmente en estas décadas del sesenta/ setenta, y explica, en parte, esta onda relacionadora de tiempos y espacios culturales.

La vida - escribe Alan Watts- es fundamentalmente un gesto, pero nada ni nadie hace ese gesto. Nada lo obliga a producir, nada lo obliga a perdurar. Porque nada lo ha provocado, sino que se produce a sí mismo,

${ }^{5}$ En el Círculo de Mujeres Poetas Dominicanas están Chiqui Vicioso, Carmen Imbert, Carmen Sánchez, Dulce Ureña y Myriam Ventura. 
libremente. Es un gesto que es movimiento, sonido, color, y así como na. die lo ha hecho, así tampoco nadie lo capta. La vida no es en modo alguno un problema, es un juego sin finalidad, una exuberancia cuyo fin es ella misma. Fundamentalmente es un gesto. Y el tiempo, el espacio y la multiplicidad son complicaciones de ese gesto ${ }^{6}$.

Quisiera suscribir una observación de Daniel Odier y Marc de Smedt, en Las misticas orientales (p. 166) ${ }^{7}$, en el sentido de esta búsqueda hacia el Oriente que fue y es siempre la angustia, angustia del hombre solo ante sí mismo.

Los creadores líricos de la generación dominicana de 1965 están ante un nuevo destino planetario: en una era post-atómica, en medio de los problemas de un mundo en vías de desarrollo o de insuficiente desarro1lo, como es el 1lamado Tercer Mundo. Es un mundo de tensiones EsteOeste-Norte-Sur. En las naciones más desarrolladas de este mundo se habla de economías post-industriales, pero en las zonas de menor desarrollo de nuestro planeta se habla y se sufre de grave desnutrición, cuando no, sencillamente, de hambre física. Este es el mundo de los poetas dominicanos de 1965: un mundo de satélites artificiales, cibernético, electrónico, donde uno ve, aun en algunas viviendas miserables de los barrios pobrísimos, en zonas marginadas de nuestras poblaciones urbanas, antenas de televisión. Pero estos poetas, como los demás moradores de nuestra América, ven una América empobrecida, endeudada, burlada desde lo doméstico; dividida en compartimentos estancos, desorientada y aun lejos de los grandes ideales unitarios bolivarianos, martianos y del maestro humanista Pedro Henríquez Ureña; una América que lucha por su mejor y mayor desarrollo en medio de retrocesos éticos y una falta de moral colectiva, solidaria, tanto a nivel continental como planetario.

Son guías, notas, para comprender mejor puntos de vista de Enriquillo Sánchez en su estudio y antología y para comprender ciertos tonos y temas de los poetas dominicanos de la generación lírica de 1965.

\section{ENTRE EL AYER Y EL MAÑANA}

Me parece importante indicar una nota que aparece en esta generación de poetas dominicanos y de manera mury marcada: es la ironía sentimental, la burla, la crítica humorística, social, que cristaliza en un poeta como Luis Manuel Ledesma, para sólo dar un ejemplo.

\footnotetext{
- Alan Watts, Cosmología gozosa (París, 1971); El budismo zen (París, 1969).

${ }^{7}$ Daniel Odier y Marc de Smedt, Las místicas orientales (Barcelona: Martínez Roca, La Otra Ciencia, 1975).
} 
Es significativo también el empleo en esta poesía de un recurso que no encontramos en las generaciones anteriores: el uso del collage, cuyas experiencias partieron desde las artes plásticas con un Braque, con un Picasso -en una de sus varias «épocas» o «edades»- y, en general, de los ángulos nuevos que trajo el cubismo y de las formas abstractas que nacen con Kandinsky.

Es curiosa la anotación (p. 186 del libro ya citado) que Odier y Marc de Smedt formulan, en el sentido de que cada metamorfosis es el gozne de una lenta maduración y que ningún fenómeno evolutivo ha nacido nunca de una ruptura.

Deseo recordar, finalmente, que los poetas dominicanos de 1965 han examinado la herencia recibida en el curso del río de la poesía dominicana y el de la poesía continental y universal. Si, por una parte, el río de la cultura hispana está presente en poetas de esta generación $-\mathrm{y}$ bien asimilado-, algún poeta ha intentado, como José Manuel Soto Jiménez, incorporar raíces indígenas, en Poesía: Areito del Cimú. Canto de Origen, Santo Domingo, 1979, y algún otro poeta, como es el caso de Cándido Gerón, ha conseguido, en sus últimos e intensos libros líricos una interesante y extensa incorporación poética de los mitos afro-dominicanos, afro-antillanos y greco-antillanos, de un indudable valor simbólico, alegórico, a su poesía, trabajando desde el parasurrealismo y los territorios del inconsciente colectivo.

Entre otras voces, otros nombres, otras aportaciones, hay que citar también a Goudy Pratt, Rómulo Medrano Marte, Grey Coiscou Guzmán, Rafael Abreu Mejía, Nemén Michel Terc, en las avanzadas de esta generación. Y luego, a Domingo de los Santos, Oscar Gil Díaz, Héctor Díaz Polanco, León David, Apolinar Núñez, Elpidio Guillén Peña, Edgardo Hernández Mejía, Orlando Gil, Orlando Morel, Denis Mota, Diómedes Núñez Polanco, Pedro Peix, Radhamés Reyes Vázquez, Aquiles Julián, Tomás Modesto, Manuel Marcano Sánchez, Salvador Santana, Abil Peralta Agüero, Pedro Pompeyo Rosario, Pedro José Gris y otros. Duele, a veces - como ahora-, presentar a estos poetas en esta constelación de nombres, pero sin adentrarse a cada mundo, a cada planeta que forma una imagen, también, de este sistema o conjunto. Se explica la galaxia en la visión panorámica, pero nos ha quedado penetrar y explicar las individualidades de este conjunto.

Las notas biobibliográficas de todos estos poetas figuran desde la página 476 hasta la 484 en mi ya citado libro Los poetas dominicanos del 1965. Una generación importante y distinta. 


\section{DE LA SOLTURA ALEGRE AL CUIDADOSO RIGOR}

Si el estudio y antología sobre sus compañeros que realiza Enriquillo Sánchez da esa impresión del tiro con arco, con los ojos cerrados, debido a la seguridad inconsciente de acertar, el estudio y antología de Andrés L. Mateo, Poesía de postguerra / Joven poesía dominicana (Santo Domingo, 1981), nos da una impresión de rigor y sobriedad.

En el estudio inicial de Enriquillo Sánchez hay observaciones que conviene no dejar pasar así como así. Son necesarias para los estudiosos dentro de la República Dominicana: «La crítica científica no puede prescindir del texto literario, del hecho literario concreto, pero tampoco deberá prescindir de la situación en que ese texto se produce» (p. 3). Es eco fiel de la sabia advertencia de Ortega y Gasset sobre el ser y la circunstancia y es, también, aquello en lo que insistía Víctor Raúl Haya de la Torre: la necesidad de tomar en consideración el espacio-tiempo histórico que rodea a la obra.

Algún comentarista dominicano de la poesía ha querido colocarse «por encima del texto» y ejercer un papel de fiscal de la poesía dominicana, sin comprender que en el hecho poético - hoy, ayer y los habrá mañana- hay factores socioculturales que contribuyen a explicarlo, a hacerlo sentir mejor, a rodearlo de mayor luz. No es acertado suprimir, ni en los poetas dominicanos de $1965 \mathrm{ni}$ en las generaciones anteriores y en las que vendrán más tarde, aquella advertencia orteguiana de las circunstancias. La poesía es un hecho humano.

El análisis rítmico de los textos es importante, pero no es todo. Hay que pensar en el contenido de la forma. Hay que atender también a la renovación del lenguaje poético y al léxico.

Desde hace tiempo, y semanalmente, en El Caribe de Santo Domingo, María del Carmen Prodoscimi de Rivera realiza una labor desde hoy hacia mañana y contribuirá a formar buenos lectores de poesía. Hay también unos valiosos nombres más ${ }^{8}$. Y para volver a Poesía de postguerra/Joven poesía dominicana, de Andrés L. Mateo, es un buen ejemplo de un ensayo lúcido, de una antología rigurosa y, a la vez, abierta sobre los poetas dominicanos de 1965.

${ }^{8}$ La contribución a la investigación, al análisis poético y en parte a su divulgazión desde libros y páginas literarias, revistas y la prensa en general, es importante desde la obra de Manuel Rueda, Freddy Gatón Arce, Antonio Fernández Spencer, Ramón Francisco, Bruno Rosario Candelier, José Alcántara Almánzar, Daisy Cocco de Filippis, Josefina de la Cruz, Julio Cuevas, sin olvidar la misión pedagógica y divulgadora de Manuel Mora Serrano en la prensa de provincias y de la capital. Es preferible - ante el misterio de la poesía- pecar de generoso y no de mezquino. 
Si Enriquillo Sánchez contó para su obra con la muy buena colaboración de sus compañeros de generación y con la tarea de Soledad Alvarez para las notas biobibliográficas, Andrés L. Mateo tuvo a su favor el Centro de Investigaciones Literarias de la Biblioteca Nacional de Santo Domingo para su edición de 1981, impresa en la editora Alfa y Omega de la capital dominicana. E1 prólogo va desde la página 7 a la 11, y la antología — muy equilibrada - incluye poemas de Norberto Iames Rawlings, Enriquillo Sánchez, Mateo Morrison, Cayo Claudio Espinal, Alexis Gómez, Tony Raful, Enrique Eusebio, Andrés L. Mateo, José Enrique García, Soledad Alvarez, Federico Jovine Bermúdez, José Molinaza. Creo que en 1981, año de la aparición de Poesía de postguerra / Ioven poesía dominicana, de Andrés L. Mateo, era muy difícil una antología mejor sobre los poetas de 1965, con mayor seriedad, selección y apertura.

\section{O'TROS ESTUDIOS, OTRAS VISIONES E IMPRESIONES}

Los poetas de 1965 promueven en Listin Diario, de Santo Domingo, un primer trabajo panorámico, una visión conjunta del quehacer cultural dominicano, que parte desde la aparición de esta generación («Diez años de cultura literaria», sábado 26 de enero de 1974, Artes y Letras, año 1, número 1). E1 ensayo está ilustrado con quince clisés, que son quince carátulas referentes a tapas o portadas de publicaciones relacionadas con los poetas de 1965. El recuento abarca hasta 1973. El estudio es cronológico y toma en cuenta los factores, las circunstancias históricas y sociopolíticas.

El suplemento Aquí. La Noticia, Santo Domingo (domingo \& de juaio de 1975, número 97), gira en torno a la Joven poesía dominicanal Poesía de postguerra. Corresponde a Tony Raful, Mateo Morrison, Enrique Jovine, Enrique Eusebio. Me parece un documento importante para el estudio de los poetas de 1965: se trata de una interesante conversación grabada, que está apoyada por textos líricos de Enrique Eusebio, Enriqui1lo Sánchez, Luis Manuel Ledesma, Tony Raful, Alexis Gómez, Mateo Morrison, Soledad Alvarez. Este suplemento ofrece, además, información biobibliográfica en relación con los poetas de 1965.

Con motivo del primer Foro Latinoamericano de la Joven Poesía, efectuado en la Biblioteca Nacional de Santo Domingo, desde el 1 hasta el 7 de diciembre de 1975, dirigí a los delegados del comité organizador -Alexis Gómez, Enrique Eusebio y Mateo Morrison- una tesis que fue publicada para cubrir el suplemento entero de Aquí. La Noticia, Santo Domingo (domingo 12 de diciembre de 1975, número 123). Después de 
una introducción, mi tesis aborda los temas y subtemas: «La joven poesía en un tiempo joven», "La poesía latinoamericana en los últimos diez años», «Algunas otras características: los movimientos y las tendencias influyentes en general» (sobre los poetas dominicanos de la generación de $1965)$, «Otras observaciones», «Otras circunstancias determinantes», «Joven poesía y poesía nueva».

En la Enciclopedia Dominicana, Santo Domingo, 1976 -impresa en Barcelona-, en el tomo IV, desde la página 144 hasta la 149, Jeannette Miller publicó su ensayo «Poesía joven (1960-1975)». A los que llamo poetas de 1965, Jeannette Miller los califica como poetas del sesenta y habla de su lenguaje directo. Incluye a René del Risco y Bermúdez, Grey Coiscou Guzmán, Miguel Alfonseca, Juan José Ayuso, Jeannette Miller, Jacques Viau, Héctor Dotel, Antonio Lockward, Rafael Añes Borgés y otros.

Finalmente, me parece que la tesis para optar a una licenciatura de Letras en la UASD sobre los poetas de la generación de 1965, de Miguel Angel Perdomo, es un trabajo acucioso, bien organizado, con abundantes notas y 47 fichas bibliográficas. Se trata de un estudio minucioso y exigente a partir de la vanguardia de la generación de 1965. Fue publicado por la revista Eme Eme, Estudios dominicanos, de la Universidad Católica Madre y Maestra de Santiago de los Caballeros (números 43-44, julio-agosto y septiembre-octubre de 1979).

Algunas obras Claves de los poetas dominicanos DE 1965, GENERACIÓN AMPLIADA

Cada generación poética deja algunos libros y cuadernos que sirven para identificar sus temas y tonos, sus preocupaciones y sus contenidos. Un día interesa leer o releer el conjunto de estas publicaciones. Ofrezco la selección que de modo muy personal he hecho. Algunos poetas de esta generación no han reunido o seleccionado su obra en libro y permanece un tanto dispersa en revistas, páginas o suplementos literarios.

Sobre los libros claves de esta generación se podrá hacer un día, con suficiente perspectiva, un trabajo más prolijo. Doy mis impresiones a modo de un modesto borrador. En este contexto pienso que debe hablarse de Vértice, Santo Domingo, 1962, Colección Baluarte, de Goudy Pratt, que viene a ser una de las voces más adelantadas en el surgir de esta generación. René del Risco publica en 1967 — ien Santo Domingo?Viento frío, en poesía, pues tiene otra obra de 1973 que no es del género lírico.

Raíces, de Grey Coiscou Guzmán, publicado en 1959, Santo Domin- 
go. Brigadas Líricas publica una nota sobre la autora en el número 2, de enero de 1962. Grey Coiscou vendría a ser una de las adelantadas de esta generación en cuanto a su aparición en la poesía dominicana. De Nemen Michel Terc (1939), que ha publicado sus libros en España y en la Florida, EE. UU., no me he resuelto a marcar un libro clave [entre Primeros poemas (1972), Contra el tiempo (1972), Palabras de tierra (1977)]. En cuanto a Juan José Ayuso (1940), poeta de indudable importancia en esta generación, publica su obra más significativa después de haberla dado a conocer en revistas y las páginas literarias de El Nacional y de Ahora.

Miguel Alfonseca (1942) tiene dos libros representativos de esta generación: Arribo de la luz (1965) y La guerra y los cantos (1966). Jacques Viau Renaud -nacido en Port-au-Prince en 1942 y muerto en abril de 1965- fue incorporado casi desde niño a la cultura dominicana a través de su residencia en el país. Un libro símbolo es Nada permanece tanto como el llanto (La Habana, 1974). La edición dominicana es de 1965, aunque no tiene indicación de Santo Domingo.

Los poemas del ferrocarril central (Santo Domingo, 1971), de Antonio Lockward Artiles (1943); Sobre la marcha (1969) y La provincia sublevada (Santo Domingo, 1972), de Norberto James Rawlings (1945), con Huellas de la ira (Santo Domingo, 1974), de Jovine Bermúdez (1944), marcan, también, un clima expresivo de esta generación.

Pedro Vergés (1945) es un poeta que da a su generación una obra prestigiosa, editada en España por la Colección El Bardo en 1971: Juegos reunidos, y por la consagradora Colección Adonais - colección que dirige en Madrid el poeta Luis Jiménez Martos y edita Rialp-. Vergés obtuvo, en 1976, el accésit del Premio Adonais con Durante los inviernos, editado en Madrid al año siguiente.

Formulas para combatir el miedo (Santo Domingo, 1972), de Jeannette Miller (1945); Poesía 1 (1969), de Andrés L. Mateo (1946); Aniversario del dolor (Santo Domingo, 1973), de Mateo Morrison (1947); Meditación alrededor de una sospecha (Santiago de los Caballeros, 1977), de José Enrique García (1948); Desde la presencia del mar hasta el centro de la vida (1973) y Consignas \& sub-versiones (Santo Domingo, 1979), de Enrique Eusebio, y Poemas decididamente fuñones (1972), de Apolinar Núñez (1946), son libros y cuadernos líricos que hay que releer o leer con atención, porque significan vías y logros expresivos, característicos de los temas, tonos y tendencias de los poetas dominicanos de 1965.

Otros libros que me parecen significativos, desde la pluralidad de sus búsquedas y hallazgos, son: Encima de la lluvia (1970) e Imágenes del litoral (1973), de Edgardo Hernández Mejía (1948); Epidermis del camino (1977), de Orlando Gil (1949); Agua secreta, Debajo de la piel y 
otros poemas anónimos (1978), de Josefina de la Cruz (1949); Oficio de post-muerte (1973), de Alexis Gómez (1950); La esperanza y el yunque (1972), de 'Wilfredo Lozano (1950); Asombro de los tiempos (1973), Huellas de dolor (1974), Canto a Orlando (1976), Canto infinito a Salvador Allende (1979), Canto triste a una niña que nunca conoci (1980), Euridice desde las memorias y las pasiones (1981) y El invencible de los tiempos (1982), de Cándido Gerón (1950).

Aquí encontramos dos maneras de dar y editar la obra lírica: mientras Enriquillo Sánchez y Luis Manuel Ledesma (1949) han ido dejando la obra poética en páginas literarias, revistas y suplementos literarios dominicanos, Cándido Gerón ha mantenido una vocación de ofrecer su poesía en cuadernos y libros impresos y se ha inclinado, así, a trabajar una unidad temática en cada cuaderno y abarcando una variedad de temas desde los sociales hasta los metafísicos.

No sólo se ha ocupado de su obra personal $-\mathrm{y}$ esto me parece muy significativo-, sino, además, de la difusión de textos de sus compañeros de generación y de otras generaciones desde su revista Análisis. Siendo director de la Biblioteca Nacional de Santo Domingo, creó la Colección Orfeo, con un ritmo - mientras escribo- que ha pasado la cincuentena de títulos editados y ha favorecido, en el plano editorial, a la generación de 1965, confirmando y dando a conocer nuevos valores. Ha editado, además, nombres representativos de las generaciones anteriores, aparte de interesantes obras de estudios ensayísticos sobre la poesía dominicana. Volveré, al final, sobre el tema.

Tony Raful (1951) puede mostrar cuatro libros indicadores de los temas y tonos generacionales: La poesía y el tiempo (1973), Gestión de alborada (Santo Domingo, 1973), Abril, nacen alas delante de tus ojos (Santo Domingo, 1980) y sus Visiones del escriba (1981). Ha mantenido, con Pedro Peix y Andrés L. Mateo, su difusión radial de la acción creadora en poesía - su difusión y comentarios-, y cuando estuvo de director de la Biblioteca Nacional, fomentó el Centro de Investigaciones Literarias de la Biblioteca Nacional de Santo Domingo, logrando editar una antología sobre la nueva poesía dominicana: Poesía de postguerra / Joven poesía dominicana (1981), recopilada por Andrés L. Mateo, y un trabajo amplio, antológico, sobre la narrativa dominicana, obra de Pedro Peix.

Ultimo universo (Santo Domingo, 1972), de José Molinaza (1951); La muerte en el combate (1973), de Radhamés Reyes Vázquez (1952); poemas agónicos (Santo Domingo, 1974) y Del desamor y otras espadas, de Rafael García Bidó (1953); De puño y letra (Santo Domingo, 1981), de Manuel Marcano Sánchez (1954); Banquetes de aflicción (Santo Do- 
mingo, 1979), de Cayo Claudio Espinal, son títulos que hay que tener especialmente presentes a la hora del recuento del trabajo lírico de esta generación de 1965.

Un estímulo importante y dignificativo para el trabajo y la edición de algunos de los valores de esta generación de 1965 ha sido la organización esmerada - y oportuna selección- de los Premios «Siboney» de poesía. Bastaría recordar los nombres de Cayo Claudio Espinal, Rafael García Bidó, Manuel Marcano Sánchez, Juan Carlos Mieses, y el análisis de los libros premiados, para apreciar la importancia y el acierto de los Premios «Siboney» en la poesía dominicana.

Hay que agregar — como indiqué poco antes- el estímulo despertado para la edición de obra inédita valiosa, en los poetas de 1965, que la Colección Orfeo ha brindado desde la Biblioteca Nacional de Santo Domingo. Cabría destacar, en el catálogo, Antología poética, de José Enrique García; Paraiso de la memoria, de Pedro Peix; Las memorias del deseo, de Radhamés Reyes Vázquez; Antología poética, de Rómulo Medrano Marte; Parrhisian, de Salvador Santana; Vuelta al cantar de los cantares, de Tomás Castro; Luz de los cuerpos, de Sally Rodríguez; Imagen repetida en múltiples septiembres, de Sabrina Román. Todos libros de poetas de 1965 y otros que se encuentran en proceso de impresión. Esta labor, comenzada en 1985, se continuó hasta 1986, bajo la orientación editora de Gerón y su equipo. Y recordemos, para cerrar el recuento, el libro de una niña de diecisiete años, que nació en Pimentel en 1965, o sea, el año mismo de la Guerra de Abril, que ha servido para darle nombre simbólico a esta generación: Tiempo del olvido (Santo Domingo, Taller, 1980), de Taiana Mora Remis, se inicia con poemas escritos a los siete años y es un recorrido lírico hasta los poemas de los quince años. En un poema, escrito a los trece años, Taiana dice que «la tierra habla dialectos locos extraviados».

\section{PARA UN LECTOR DE IMÁGENES}

En mi obra sobre los poetas dominicanos de 1965 emprendí un diccionario de imágenes que ocupa el capítulo XVI, desde la página 415 hasta la 443. Al lector curioso, abierto, inquieto - que es siempre el que completa al autor-, le interesará esta galaxia lírica de la última generación dominicana. El telescopio y el microscopio nos muestran, igualmente, la vida. Una imagen también la muestra. Y la poesía es parte de la vida.

Quisiera recordar, para cerrar estas notas, unas palabras de un gran maestro, que tanto nos ayudó - con Juan Ramón Jiménez y Jorge Gui- 
llén- en nuestra aventura poética en la capital dominicana durante la Segunda Guerra Mundial y en la inmediata post-guerra. Tuvimos a Pedro Salinas en la vieja ciudad de Santo Domingo de Guzmán (eje del encuentro de dos culturas y, luego, de tres; de los descubrimientos y colonización del viejo, nuevo, mundo, según se le mire desde Europa o desde América).

Pedro Salinas fue a un memorable curso, breve, a la Universidad de Santo Domingo, sobre Rubén Darío. Y en su visita aprovechó el maestro para reunirse - cordial y fraterno- con los que editábamos La Poesía Sorprendida, la revista y sus ediciones. Llevado de su bondad y fervor, nos sugirió títulos y cortenidos para nuevas secciones que deseábamos incorporar a la revista. Y -como Juan Ramón Jiménez o Jorge Guillénnos entregó poemas suyos, inéditos y valiosísimos, para los que, a veces, pensábamos que estábamos aislados en la antigua isla Española.

En Aprecio y defensa del lenguaje (Editorial Universidad de Puerto Rico, 1974) escribió Pedro Salinas:

Al hombre le preocupa su lengua. ¿Por qué será? ¿Por pura curiosidad intelectual, por urgencia desinteresada de su mente? No lo creo.

Le preocupa por una motivación profundamente vital. Le preocupa porque se ha dado cuenta del poder fabuloso, y en cierto modo misterioso, contenido en esas leves celdillas sonoras de la palabra. Porque las palabras, las más grandes y significativas, encierran en sí una fuerza de expansión, una potencia irradiadora, de mayor alcance que la fuerza física incluso en la bomba, en la granada. Por ejemplo, cuando los revolucionarios franceses lanzaron, desde lo alto de las ruinas de la Bastilla al mundo entero, su lema trino: «libertad, igualdad, fraternidad», estos tres vocablos provocaron, no en París, no en Francia, no en Europa, sino en el mundo entero, una deflagración tal en las capas del aire de la historia, que desde entonces millones de hombres vivieron o murieron por ellos, o contra ellos; y ellos siguen haciendo vivir o morir hoy día.

Los poetas dominicanos de la generación de 1965 promoverán nuevos estudios, nuevos análisis y atención, como otros poetas de generaciones paralelas en el mundo de hoy. El conjunto de los poetas dominicanos de 1965 me parece interesante y aleccionador; corresponde a su espaciotiempo histórico y es fiel a las circunstancias de la etapa histórica que vivimos, expresada desde la poesía.

Les debo, como lector, no pocas lecciones, y tengo la sinceridad y el gusto de confesarlo al final -de estas notas sobre ellos, donde expreso también aquello que en las universidades de Bonn, Marburg, Tübingen y Wierzburg decía en sus lecciones, en nuestro tiempo, el estudioso de nuestros clásicos, el profesor doctor Heinz Schulte-Herbrüggen: que el lenguaje es un medio para apoderarse mentalmente del mundo. 